\title{
Cataracts in childhood leukaemia
}

\author{
ANDREW J ELLIOTT,' A OAKHILL, ${ }^{2}$ AND S GOODMAN ${ }^{3}$ \\ From the 'Bristol Eye Hospital, the ${ }^{2}$ Hospital for Sick Children, Bristol and the ${ }^{3}$ Radiotherapy Centre, Bristol \\ Royal Infirmary
}

SUMMARY The incidence and severity of cataract were studied in 37 children who had completed treatment for acute lymphoblastic leukaemia. Twelve $(32 \%)$ had posterior subcapsular lens opacities. Treatment had included corticosteroids and cranial irradiation, but no dose relationship was evident. The boys were more severely affected than the girls. Although none of the lens opacities was optically significant, clinicians should be aware of the potential risk to vision.

Following a recent observation in the United States that three out of 50 treated leukaemic children had small and asymptomatic posterior subcapsular lens opacities it was decided to examine the eyes of children treated for acute lymphoblastic leukaemia at the Hospital for Sick Children, Bristol.'

Corticosteroids have a well established role in the treatment of leukaemia, and cranial irradiation is now routinely used to prevent meningeal relapse. Since both ionising radiation and steroids are cataractogenic, particular attention was paid to these factors.

\section{Patients and methods}

All children who had completed treatment and remained in remission were asked to attend for examination. Best corrected acuities were obtained and pupils dilated with cyclopentolate to allow detailed examination of the lens and retina.

Lens opacities were assessed with a slit-lamp and direct ophthalmoscope and were then carefully drawn to allow sequential assessment. Opacities were graded according to Crews' classification, ${ }^{2}$ and, after taking into account other relevant factors such as squint or amblyopia, an estimate of the optical significance of the cataracts was made.

All assessments were made by one examiner, who was unaware of treatment protocols.

\section{Results}

In response to 38 postal requests 37 children aged between 8 and 22 years attended for examination,

Correspondence to Dr A J Elliott, Bristol Eyc Hospital, Outpatients Department, BRI Yard, Lower Maudlin Street, Bristol 1. their disease having been diagnosed between 1967 and 1979. All were in remission and off treatment.

Seven of the 14 boys had evidence of posterior subcapsular cataract, but only five out of the 23 girls were so affected. A total of 12 children $(32 \%)$ had lens opacity.

Crews ${ }^{2}$ divided adult steroid induced cataract into four grades of severity. Only grades I (occasional posterior subcapsular opacities or vacuoles in the central region with or without distortion of the specular reflex) and II (small clusters of posterior subcapsular opacities remaining discrete) were seen. Details are given in Table 1.

All children had received steroids in various dosages and protocols. There was no dosage difference between affected and unaffected children (Table 2). A wide range of dosage was represented in each group. As little as $1.1 \mathrm{~g} / \mathrm{m}^{2}$ prednisone was associated with cataract, yet one child received 17.6 $\mathrm{g} / \mathrm{m}^{2}$ without ill effect. Mean daily dosages were not compared in view of the pulsed nature of the treatment.

Likewise both groups had similar doses of cranial irradiation, though the range of dosage was, as

Table 1 Grades of severity of cataract in affected children

\begin{tabular}{|c|c|c|c|c|c|}
\hline \multirow{2}{*}{$\begin{array}{l}\text { Patient } \\
\text { No. }\end{array}$} & \multicolumn{2}{|l|}{ Boys } & \multirow{2}{*}{$\begin{array}{l}\text { Patient } \\
\text { No. }\end{array}$} & \multicolumn{2}{|l|}{ Girls } \\
\hline & Right & Left & & Right & Left \\
\hline 1 & II & II & 8 & I & I \\
\hline 2 & II & II & 9 & I & $\mathrm{O}$ \\
\hline 3 & I & II & 10 & I & $\mathrm{O}$ \\
\hline 4 & I & I & 11 & I & $\mathrm{O}$ \\
\hline 5 & I & I & 12 & I & $\mathrm{O}$ \\
\hline 6 & I & $\mathrm{O}$ & & & \\
\hline 7 & $\mathrm{O}$ & I & & & \\
\hline
\end{tabular}


Table 2 Total steroid dose and total cranial irradiation dose (nominal)

\begin{tabular}{lll}
\hline & Prednisone $g / \mathrm{m}^{2}$ & $c G y$ \\
\hline Lens opacities & $6 \cdot 5(1 \cdot 1-15 \cdot 3)$ & $2290(2000-2400)$ \\
Normal & $5 \cdot 2(1 \cdot 1-17 \cdot 6)$ & $1940(1800-2400)$, \\
& & and 3 patients \\
& & received none
\end{tabular}

Table 3 Average age at diagnosis of leukaemia and time after cessation of treatment

\begin{tabular}{lll}
\hline & Age at diagnosis $(y r)$ & $\begin{array}{l}\text { Time off treatment } \\
(y r)\end{array}$ \\
\hline Lens opacitics & $5 \cdot 2(1 \cdot 8-11)$ & $5 \cdot 8(2-10 \cdot 5)$ \\
Normal & $6 \cdot 7(1 \cdot 8-15.1)$ & $5 \cdot 1(0 \cdot 3-10.4)$ \\
\hline
\end{tabular}

expected, much smaller. The only three children who received no cranial prophylaxis did not have lens opacities. Development of cataract could not be correlated with the radiation field geometry, fractionation, type of machine used, use of sedation, or the observation of restlessness during radiotherapy.

Those with lens opacities were on average younger at the time of diagnosis, but this difference was not significant (Table 3 ).

One boy with bilateral grade II lens opacities had a visual acuity of $6 / 15$ in each eye, but he was also mentally retarded and highly myopic, and it was considered that the opacities were not fully responsible. The other boys with grade II cataracts had an acuity of $6 / 6$ in each eye.

\section{Discussion}

With increasing acceptance that childhood leukaemia is no longer an inevitably fatal disease more attention is being focused on the long-term complications of treatment. ${ }^{3}$ Posterior subcapsular cataract appears to be one of these, though fortunately the visual consequences have been slight.

It is presumed that lens opacities result from a toxic effect of various therapeutic agents on the lens. Many agents have ocular toxicity ${ }^{4}$; this study has examined two of the most likely candidates.

Black et al. first observed the cataractogenic property of steroids in patients with rheumatoid arthritis. Males predominated, though this finding was not analysed further. Crews confirmed the original observation and noticed a dose relationship. ${ }^{2}$ Dikshit and Avasthi ${ }^{h}$ made a similar observation in children with nephrotic syndrome treated with corticosteroids, and other authors have since contributed their observations. ${ }^{7-9}$

The dose relationship has not been observed so consistently as in adults, and a recent study in Leeds did not show such a relationship in children with nephrotic syndrome "I"; $14 \%$ had cataract and in only one child was vision reduced (to 6/9).

The pathogenesis of steroid cataract remains unclear and there is no animal model."

The incidence, severity, and localisation of the lens opacities in this study are consistent with a steroid aetiology, but the slight trend to unilaterality raises the possibility of a lateralising cause such as cranial irradiation applied asymmetrically due to head movement or tilt. Even with precise screening the lens would receive a small dose, due both to attenuation of the beam by the shielding and to scatter. $X$-irradiation causes posterior subcapsular cataract indistinguishable from those observed in this study. Merriam and Focht ${ }^{12}$ have extensively studied the subject and correlated severity and time of onset with dosage. The mechanism appears to be inhibition of mitosis in the germinative epithelium of the lens causing cortical opacities after a latent period. The minimum cataractogenic dose in adults is about 200 cGy, but no detailed data exist for children, in whom the lens may be more sensitive..$^{213}$

Examination of two potential cataractogenic influences in this study has revealed no clear aetiology of lens opacities in treated leukaemia. A combination effect would be feasible. Individual susceptibility of certain children is also possible and has been suggested before in reference to steroid cataract. ${ }^{.11}$ Whatever the mechanism, lens opacities do occur and it is important that clinicians should be aware of the potential threat to sight.

Dr Oakhill is supported by the Leukacmia Rescarch Fund. Dr Goodman is supported by a Medical Research Council Grant.

\section{References}

1 Nesbit ME, Robison LL, Sather HN, Mcadows AT, Ortega JA, Hammond GD. Follow up study of long-term survivors of childhood acute lymphoblastic leukacmia. Childrens Cancer Study Group, Los Angeles 3rd International Symposium on Therapy of Acute Leukacmias 1982 Rome, Italy.

2 Crews SJ. Posterior subcapsular lens opacities in patients on long term corticosteroid therapy. Br Med J 1963; i: 1644-7.

3 Chessells J. Recent advances in paediatrics 6. Edinburgh: Churchill Livingstonc, 1981: 157-77.

4 Fraunfelder FT, Mcyer SM. Ocular toxicity of antincoplastic agents. Ophthalmology 1983; 90: 1-3.

5 Black RL, Oglesby RB, von Sallman L, Bunim JJ. Posterior subcapsular cataracts induced by corticosteroids in patients with rheumatoid arthritis. JAMA 1960; 174: 166-71.

6 Dikshit SK. Avasthi PN. Posterior Ienticular opacitics in children on corticosteroid therapy. Indian J Pediatr 1965; 32: 93-96.

7 Havre DC. Cataracts in children on long term corticosteroid therapy. Arch Ophthalmol 1965; 73: 818-21.

8 Kobayashi Y, Akaishi K, Nishio T, Kobayshi Y, Kimura Y, Nagata M. Posterior subcapsular cataract in nephrotic children receiving stcroid therapy. Am J Dis Child 1974; 128: 671-3. 
9 Fine RN, Offner G, Wilson WA, Mickey MR, Pennisi AJ, Malckzadeh MH. Posterior subcapsular cataracts: posttransplantation in children. Ann Surg 1975; 182: 585-9.

10 Brocklebank JT, Harcourt RB, Meadow SR. Corticosteroidinduced cataracts in idiopathic nephrotic syndrome. Arch Dis Child 1982; 53: 30-4.
11 von Sallmann L, Caravaggio LL, Collins EM, Weaver K. Examination of lenses of steroid-treated rats. Am J Ophthalmol 1960; 50: 1147-51.

12 Merriam GR, Focht EF. Clinical study of radiation cataracts and the relationship to dose. AJR 1957; 77: 759-85.

13 MacFaul PA, Bedford MA. Ocular complications after therapeutic irradiation. BrJ Ophthalmol 1970; 54: 237-47. 